\title{
Archival Cataloging and the Archival Sensibility
}

IF YOU ASK CATALOGERS about the relationship between bibliographic and archival cataloging, more likely than not their answers will stress divergence over convergence. Potential arguments about the differences encompass issues surrounding books versus manuscript materials, items versus collections, and an emphasis on artifactual description versus content and context description. The truly divergent cases should not distract us from the significant areas of convergence, however. In particular, the cataloging of rare books and materials shows meaningful similarities across bibliographic and archival cataloging. There is a real benefit to focusing on where practices converge. Focusing on convergence provides the advantage of allowing a common space for catalogers to share practices, reduce duplication of effort, and create data that work well together. By stressing likeness over distinction, we can decrease the hindrance of boundaries between the communities and improve overall cataloging practices.

This paper addresses the fundamental components of archival description to draw parallels to the description of rare books and materials. It traces the traditions that shaped the current archival descriptive framework and discusses the fundamental components of archival description. The first section concludes on what it means to approach something "archivally." The second section focuses on the role of contextual information in archival cataloging and makes connections to the description of rare books and materials. Because of its centrality in archival description, contextual information is examined in light of the various functions that it serves. A concluding section looks at the use of MARC for archival cataloging and returns to the theme of convergence to demonstrate that cataloging communities can benefit from sharing and increased communication.

\section{Archival Cataloging Then and Now}

While archival description enjoys a long history, archival cataloging with the MARC format began in the 1980s with the publication of the first edition of Archives, Personal Papers, and Manuscripts by Steven L. Hensen for the Library of 
Congress. ${ }^{1}$ The development of descriptive standards contributes to an understanding of the application of that description in the MARC environment. The first modern set of rules for archival description was laid out by three Dutch archivists to fulfill a directive from the Netherlands Association of Archivists at the end of the 19th century. ${ }^{2}$ While the Manual for the Arrangement and Description of Archives is over 100 years old and was created with a specific archival tradition in mind (that in the Netherlands), the principles laid out by Muller, Feith, and Fruin transformed Western archival traditions and continue to influence current descriptive practices. For instance, Describing Archives: A Content Standard (DACS) references Muller, Feith, and Fruin in Principle 2, which discusses the organic nature of archival collections. ${ }^{3}$

The development of the current archival description framework owes much to the Manual, which was translated into English in the 1940s, but it also relies upon the record-keeping activities of American archivists and historical societies. Davis argues in her article "Descriptive Standards and the Archival Profession" that the idiosyncrasies of archival materials were a guide for the descriptive tools created to provide access to those materials. These idiosyncrasies resulted in the development of the finding aid, register, or inventory document that is used throughout archival repositories. She further delineates the traditions as they were developed through two distinct communities: governmental or institutional archives and historical manuscripts maintained through historical societies. She concludes that the descriptive traditions of archival cataloging derive from both the nature of the materials and the nature of the profession. ${ }^{4}$

In examining the differences between bibliographic cataloging and archival description, Smiraglia argues that the traditions developed exclusively from one another, stating that the communities resulted in "seemingly very different retrieval tools

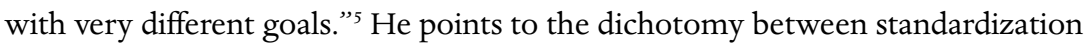
and uniqueness, which is a common conception in comparing descriptive activities. He then identifies three areas in which these differences can be delineated: physical, intellectual, and theoretical approaches to retrieval. He does, however, identify the common goal of control and access over the materials. ${ }^{6}$

1. Steven L. Hensen, Archives, Personal Papers, and Manuscripts (Washington: Library of Congress, 1983).

2. S. Muller, J.A. Feith, and R. Fruin, Manual for the Arrangement and Description of Archives (Chicago: Society of American Archivists, 2003).

3. Describing Archives: A Content Standard (Chicago: Society of American Archivists, 2004), xii.

4. Susan E. Davis, "Descriptive Standards and the Archival Profession," Cataloging \& Classification Quarterly 35, 3/4 (2003): 291-308.

5. Richard Smiraglia, "New Promise for the Universal Control of Recorded Knowledge," Describing Archival Materials: The Use of the MARC AMC Format, ed. R. Smiraglia (New York: Haworth Press, 1990), 2 .

6. Smiraglia, 4. 
An examination of the path followed to arrive at current descriptive standards in the archival profession appears to corroborate Davis' and Smiraglia's reading. However, the adoption of structure standards such as Machine Readable Cataloging (MARC) highlights the convergence of practice and identifies areas where archival descriptive work should no longer be considered completely different from other cataloging practices. While the development of different traditions can and has been traced, it is less in our interest now to focus on those differences and more important and useful to focus on the similarities. As data that represent a variety of formats and come from a variety of traditions continue to be aggregated, we need to acknowledge that the work of cataloging shares some fundamental practices.

If considered from an archival perspective, the descriptive framework is laid out according to well-articulated principles that unravel the nature of archival materials and the role that description plays in conveying information about those materials. Therefore, because archivists are working with aggregates of material, defined by the principles of provenance and original order, description needs to reflect that disposition. This has led to the creation of the finding aid. Archival finding aids are the primary access tool for archivists. It is this document structure that provides the most information about a collection, combining information about the content, structure, context, and administrative details of the materials.

While finding aids represent multilevel description, single-level records can be and are derived. These are often represented in MARC records for inclusion in integrated library systems (ILS) and bibliographic utilities, such as WorldCat. This development, in particular, has enhanced the reach and exposure of archival materials much more than any other advance. The relationship between the MARC record and finding aid is an important one. For any level of description created in a finding aid, a corresponding MARC record could be created (although for only that one level). Therefore, MARC records can be seen as summary description for a particular level of description.

The distinction between single-level and multilevel descriptions is a fundamental construct for archival description. Single-level description defined by DACS means that catalogers "describe archival materials at any level, from large accumulations commonly referred to by archivists as collections, record groups, fonds, or records series, to single items, and any level in between. They can, however, only describe that material at one level."” Multilevel description also describes material beginning at any level but it "must include at least one sublevel." ${ }^{8}$ This distinction provides archival catalogers the ability to consider aggregations (levels) either in isolation from

7. Describing Archives: A Content Standard, 8.

8. Describing Archives: A Content Standard, 9. 
their subparts or to consider aggregations in conjunction with their subparts. The two primary communication formats used for archival description also reflect this difference. Encoded Archival Description, developed in the 1990s and released to the archival community as Version 1.0 in 1998, was specifically developed to reflect multilevel description. As Daniel Pitti points out, "MARC was primarily designed to capture data describing a discrete bibliographic item; complex collections requiring descending levels of analysis quickly overburdened the MARC structure."' While adoption of MARC was well underway, more was needed to satisfy the multilevel characteristic of archival description.

The archival finding aid conveys significantly more information about an archival collection than does a MARC summary record. This is due to the fact that the archival finding aid is a multilevel document. Therefore, it can provide information about, for example, the collection, series within that collection, any subseries, files, or items considered by the archivist to be warranted. A MARC catalog record, in contrast, can only describe one level. The ability to link MARC records together (using the MARC fields 580 and 773) assuaged some catalogers, yet other drawbacks such as field size and limitations on the number of fields available in the 1980s and 1990s rendered MARC cataloging less appealing for the archival community. It did, however, open up the possibilities of including information about archival materials in a new arena, which drove many archivists to adopt the standard despite these problems. Pitti delineates the relationship between MARC representation and encoded finding aids, stating: "MARC AMC collection-level records and finding aids are intended to work together as parts of a hierarchical archival access and navigation model. At the top of the model, the AMC record represents a collection in the on-line catalog and leads ... to the more detailed information in the finding aid. The finding aid, in turn, leads to the materials in the collection." ${ }^{10}$ Encoded Archival Description, in other words, is only one aspect of the archival description framework, with MARC records (no longer in the AMC format since format integration in the 1990s) providing multiple entry ways to collections.

The comparison of cataloging practices between bibliographic and archival communities can be considered an intentional-organic dichotomy. The differences between the two communities can be highlighted in four interrelated areas: creation, standardization, data format, and descriptive focus. First, bibliographic items are self-consciously or intentionally created, dictating a certain awareness of the object. On the other hand, archival materials are created organically as people move

9. Daniel Pitti, "Encoded Archival Description: The Development of an Encoding Standard for Archival Finding Aids," Encoded Archival Description: Context, Theory, and Case Studies, ed. Jackie M. Dooley (Chicago: Society of American Archivists, 1998), 14.

10. Pitti, 11 . 
through their lives, either personally or professionally, with the possible exception of the creation of government or institutional records that are dictated by statute or a records management program. Similarly, the creation of bibliographic materials today is part of a standardized process, whereas there is no standard means of generation for archival materials. Second, but related to and dependent on the first, is that description is generated primarily through means of transcription for bibliographic materials and the primary focus of that description is to reflect the artifact. In contrast, archival description is primarily based on abstraction and focuses on the content more so than the artifact. These differences can present a wide gulf between the two description communities.

The rare book descriptive community represents the bridge between these ends of the spectrum. In the description of rare books, catalogers often turn to external sources to adequately describe the material. Rare books represent the evolution of bibliographic artifact standardization and therefore seldom fit into the neat categories that 20th- and 21st-century books exemplify. For example, manuscripts created prior to the invention of moveable type represent significant challenges to catalogers. The archival cataloger often uses the absence of a title page as evidence of the challenges faced in the cataloging process, but that could also be said of the rare book cataloger.

\section{The Significance of Context}

Contextual information provides the foundation for commonality between the rare book and archival cataloging communities and offers a starting place for considering convergent practices. Context is a critical component of archival description. Contextual information maintains the coherence of disparate items as an interconnected whole, grounds those materials in the creation and maintenance of the records, and provides administrative information necessary for the control of those materials. As archival description has been codified in the last three decades, context has played a central role. For example, the International Standard for Archival Description (General) (ISAD[G]) indicates that the Context Area should include the name of the creator, administrative or biographical history, the archival history, and the immediate source of acquisition or transfer. ${ }^{11}$ DACS also includes context as an essential component of archival description, accounting for the description of creators as their eighth principle. ${ }^{12}$ Contextual information is also central to rare book materials. A significant number of notes outlined in Descriptive Cataloging of Rare Materials (Books) (DCRM[B]) direct catalogers to include information relevant

11. ISAD $(G)$ : General International Standard for Archival Description: Adopted by the Committee on Descriptive Standards, Stockholm, Sweden, 19-22 September 1999 (International Council on Archives, 2000), 18-22.

12. Describing Archives: A Content Standard, xv. 
to the book as it fits within the context of book history. For example, Rule 7B6.3 is for Attributions; the subcategory 7B6.3.3 on how to handle false attributions, states: "false attributions appearing in the bibliographical literature or in library catalogs may also be noted, along with the authority for the false attribution and the authority for questioning it." The edition and bibliographic history note (7B7) directs the cataloger to include relevant bibliographic history to the item being described. ${ }^{13}$ These represent just two examples from DCRM(B); contextual information can be found throughout the notes.

While context is important to both traditions, they differ regarding which context is considered. The cataloging of rare books and materials focuses on the context of bibliographic history; in describing archival materials, the context is of the collection within all (relevant) history. However, in both cases, context is essential to gain a fuller understanding of the material being described. Understanding the centrality of contextual information to both traditions illuminates just one of the areas of convergence in our practices and presents a starting point for cross-community dialogue.

\section{Conclusion: Four Questions and the Archival Sensibility}

When a cataloger approaches any material, she asks four questions:

1. Where did I get the information?

2. What system am I using?

3. Who are my users?

4. What format-specific details are there?

These four questions are answered in each of the cataloging traditions and provide the first arena for convergence. While the answers may differ across formats, the fact that we focus on these issues before beginning our descriptive work provides the groundwork for the idea that description across communities is not all that different. Yes, there are different acceptable sources of information, for instance, but each community defines those acceptable sources of information. Similarly, understanding users is important in creating any system for access. The bibliographic cataloging universe serves a much wider and less specialized audience than that of the archival cataloger, but both communities define their audience and point to specific descriptive decisions made to serve that audience. The rare book cataloger most likely serves users who straddle the environments of general bibliographic cataloging and archival cataloging. Format-specific information will ultimately inform the descriptive information that is included and the shape of that informa-

13. Descriptive Cataloging of Rare Materials (Books) (Rare Book Manuscripts Section, 2nd printing with corrections, 2008), rule 7B6.3 and 7B7. 
tion; but, no matter the item in front of the cataloger, those details will be noted and will help to craft the description.

In terms of cataloging, the archival sensibility boils down to the ability of the archivist to treat an aggregation as an "item" to be cataloged. Part of that sensibility includes the specific aspects of the archival collection, particularly in relation to the context of that collection. Context extends beyond creation to include administrative control components as outlined above. Therefore, archival cataloging can be considered an approach to material. The argument that anything can be considered "archival" disabuses the notion that archival is a quality inherent in material. It is a way of treating materials in a descriptive framework and includes the ability to see aggregations as single descriptive objects and to set the importance of contextual information into the understanding and use of those materials. The same could be said of the rare book descriptive structure. Rare books can be cataloged according to minimal AACR2 standards or they can be approached with DCRM(B) with its emphasis on context.

Descriptive communities would benefit from a refocus from divergence to convergence. The similarities in the endeavor to control and provide access to materials, paramount to the mission of all institutions, bring these communities together. While descriptive traditions may have evolved at different paces and along dissimilar paths, divergence drives a wedge between communities that can result in duplication of effort and distinctions that make little sense to users. With an emphasis on convergence, communities can learn from each other the ways in which their specializations fit into a larger descriptive framework.

\section{David M. Lesser Fine Antiquarian Books LLC}

One Bradley Road \#302, Woodbridge, CT 06525

Tel: (203) 389-8111 Fax: (203) 389-9113

Email: dmlesser@lesserbooks.com

Website: http://www.lesserbooks.com 